\title{
REVISÃO INTEGRATIVA: UM RETRATO DA MORTE E SUAS IMPLICAÇÕES NO ENSINO ACADÊMICO
}

Márcia Gabriela Rodrigues de LIMA ${ }^{a}$, Elisabeta Albertina NIETSCHE ${ }^{\mathrm{b}}$, Solange Capaverde dos SANTOS , Joice Ane TEIXEIRA ${ }^{\mathrm{d}}$, Janilene Camara BOTTEGA ${ }^{\mathrm{e}}$, Glaucia Dal Omo NICOLA ${ }^{\mathrm{f}}$, Silomar ILHA ${ }^{\mathrm{g}}$

\section{RESUMO}

Trata-se de uma revisão integrativa com objetivo de conhecer como a morte e o ensino sobre a morte e o morrer têm sido abordados em publicações científicas na área da saúde. A pesquisa foi realizada nas bases de dados Literatura da América Latina e Caribe em Ciências da Saúde e Base de Dados em Enfermagem, com os descritores "morte" e "ensino". O levantamento abrangeu as publicações nacionais indexadas entre 1998 a 2010, sendo identificados 14 artigos que compuseram o corpus do estudo. Os resultados apontaram que há despreparo dos discentes, docentes e demais profissionais da saúde para trabalhar com a morte, já que receberam pouco ou nenhum preparo em sua formação. Então, estimular as produções científicas nessa temática potencializa maior difusão desse conhecimento específico e auxilia na preparação e formação dos profissionais para o enfrentamento do morrer e da morte.

Descritores: Morte. Ensino. Enfermagem.

\section{RESUMEN}

Este estudio objetiva conocer cómo la muerte y la enseñanza sobre la muerte y morir vienen siendo abordados en las publicaciones científicas en salud. La investigación fue realizada en las bases de datos Literatura de América Latina y el Caribe en Ciencias de la Salud y Base de Datos en Enfermería con los descriptores “muerte” y "enseñanza”. La recopilación abarcó las publicaciones nacionales de 1998 a 2010, edificándose 14 artículos, los cuales compusieron el corpus del estudio. Los resultados indicaron la falta de preparación de los estudiantes, profesores y otros profesionales de la salud para trabajar con la muerte, ya que recibieron poca o ninguna preparación en su formación. Estimular producciones científicas en esa temática potencializa más difusión de ese conocimiento específico y auxilia en la preparación y la formación de los profesionales para el enfrentamiento con la muerte y el morir.

Descriptores: Muerte. Enseñanza. Enfermería.

Título: Revisión integrativa: un retrato de la muerte y sus implicaciones en la enseñanza académica.

\section{ABSTRACT}

This is an integrative literature review aimed at finding out how death, teaching about death and the dying process have been addressed in scientific publications in the health field. The research was performed using the Literatura da América Latina e Caribe em Ciências da Saúde e Base de Dados em Enfermagem(Latin America and Caribe Health Sciences Literature and Nursing Database) databases with the descriptors "death" and "teach". The survey covered national publications between 1998 and 2010, 14 articles were selected to compose the corpus of the study. The results indicated the lack of proper training by students, teachers and other health professionals to deal with death, since they had little or no preparation throughout their academic life. Thus, stimulating scientific production within this theme promotes a bigger diffusion of this specific knowledge and helps in the qualification and training of professionals to deal with death and the dying process.

Descriptors: Death. Teaching. Nursing.

Title: Integrative review: a portrait of death and its implications in academic teaching.

\footnotetext{
a Enfermeira. Mestranda pelo Programa de Pós-Graduação em Enfermagem (PPGEnf.) da Universidade Federal de Santa Maria (UFSM), Santa Maria, Rio Grande do Sul, Brasil.

b Enfermeira. Doutora em Enfermagem. Docente do Curso de Graduação em Enfermagem e do PPGEnf./UFSM, Santa Maria, Rio Grande do Sul, Brasil.

c Química. Doutora em Informática na Educação, Santa Maria, Rio Grande do Sul, Brasil.

d Acadêmica do $5^{\circ}$ semestre do Curso de Graduação em Enfermagem da UFSM, Rio Grande do Sul, Brasil.

e Acadêmica do $7^{\circ}$ semestre do Curso de Graduação em Enfermagem da UFSM, Santa Maria, Rio Grande do Sul, Brasil.

f Enfermeira. Mestranda pelo PPGEnf. da Universidade Federal do Rio Grande (FURG), Santa Maria, Rio Grande do Sul, Brasil.

g Enfermeiro. Mestrando pelo PPGEnf./FURG, Santa Maria, Rio Grande do Sul, Brasil.
} 


\section{INTRODUÇÃO}

A maioria das produções científicas na área de Enfermagem, e demais cursos da saúde, referem que os atuais conteúdos curriculares destacam, incisiva e enfaticamente, os tipos de tecnologias e medicamentos destinados à cura ou tratamento de enfermidades. Nesse contexto, a formação dos profissionais da saúde está voltada à defesa da vida e ao combate da temida inimiga: a morte ${ }^{(1)}$.

Em consequência, fomentar o ensino-aprendizagem a cerca de um tema tão pertinente quanto o processo de morrer e morte revela-se um trabalho desafiador, tanto aos docentes enfermeiros, que percebem seu despreparo para discutir esse assunto, quanto aos discentes que associam a finitude do paciente como um fracasso de seu cuidado(2). Todavia, compete ao educador encaminhar o educando para a descoberta e a prática dos valores morais, éticos e bioéticos, por intermédio dos quais a educação ganha sentido e o próprio educando se emancipa, enquanto sujeito de suas próprias ações.

Essa limitação acontece porque a morte é trabalhada dentro de uma esfera puramente biologicista, representando um evento vital oposto à vida, causador de medo, sofrimento e frustração, em detrimento de uma abordagem multifatorial determinada por aspectos biopsicossocioculturais que influenciam, direta e indiretamente, as ações e emoções de todos os sujeitos.

Por conseguinte, o termo tanatologia, com frequência, é utilizado equivocamente como sinônimo da palavra morte, entretanto, ambos diferem no sentido conceitual. Visto que, tanatologia tem sua etimologia no grego tanathos (o deus da morte) e logia (ciência), ou seja, ciência que estuda a teoria, filosofia e doutrina da morte, analisando aspectos biológicos, sociais, psicológicos, emocionais, legais e éticos à morte ${ }^{(3)}$.

Já a palavra morte tem origem no latim mortis, que significa $o$ ato de morrer, fim da vida ${ }^{(4)}$. Então, sua definição pauta-se na cessação irreversível de todas as funções corpóreas manifestadas por ausência de respiração espontânea e perda total das funções cardiovascular e cerebral ${ }^{(5)}$.

Assim, abordar conteúdos na temática de Tanatologia, durante a formação de discentes em saúde, implica em levantar questões não restritas a morte, mas também destacar a relevância da prestação de um cuidado integral, ético e humanizado ao paciente inserido no processo terminal. A esse tipo de cuidado especializado denomina-se como paliativo, que trás a possibilidade de re-humanizar o processo de morrer, visando à qualidade de vida, bem-estar e opondo-se à idéia de morte como uma doença que deve ser curada a todo custo ${ }^{(6)}$.

De qualquer forma, a questão educacional é imperativa na reformulação curricular nos cursos da área da saúde. Pois, torna-se mister que os discentes, em seu processo de formação, tenham possibilidades de vivenciar a prática de tecnologias mais simples no cuidado ao paciente terminal, como: a compaixão, respeito e o diálogo ${ }^{(7)}$.

Considerando que, o discente para aprender precisa realizar um trabalho cognitivo de análise e revisão, a fim de que os conhecimentos sejam realmente significativos e propiciem um nível mais elevado de competência. Então, a influência do docente e da sua intervenção pedagógica, diante do tema morte, é que determinará a base de formação profissional dos discentes.

Diante disso, o interesse em estudar o ensino em Tanatologia, na Enfermagem e demais cursos da saúde, sucedeu de diversas experiências, reflexões e estudos acerca dessa temática. Assim, o empenho em traçar um diagnóstico da produção científica sobre como a morte é retratada e suas implicações no ensino acadêmico, pauta-se no fato de pensar modos e maneiras de entendê-lo e, também, pela necessidade de produção científica nessa área.

Frente às colocações mencionadas, este estudo teve como objetivo geral: conhecer como a morte e o ensino acadêmico, nessa temática, tem sido abordados em publicações científicas nacionais na área da saúde. Como objetivos específicos almejaram-se: realizar o levantamento das produções científicas desenvolvidas sobre a morte e suas implicações no ensino acadêmico e analisar descritivamente os resultados das pesquisas produzidas para a construção do conhecimento na área da saúde no enfoque da temática morrer e morte.

\section{METODOLOGIA}

Trata-se de um estudo com abordagem qualitativa, realizada a partir de uma revisão integrativa, a qual tem a finalidade de reunir e sintetizar os resultados de pesquisas sobre um delimitado tema, de maneira sistemática e ordenada, sendo um instrumento para o aprofundamento do conhecimento 
a respeito do tema investigado, permitindo a síntese de múltiplos estudos publicados e conclusões gerais a respeito de uma particular área de estudo ${ }^{(8)}$. A partir disso, a elaboração desta revisão foi desenvolvida em cinco etapas: formulação do problema, coleta dos dados, avaliação dos dados coletados, análise e interpretação dos dados e apresentação dos resultados ${ }^{(8)}$.

A formulação da questão norteadora deste estudo foi definida a partir do seguinte questionamento: como a morte e o ensino acadêmico sobre morrer e morte estão sendo abordados em publicações científicas nacionais?

O estudo foi realizado por meio de busca on-line das produções científicas nacionais sobre a morte e suas implicações no ensino, em maio de 2011. A captura dessas produções foi processada por meio da Biblioteca Virtual em Saúde (BVS), sendo utilizadas as bases de dados: Literatura da América Latina e Caribe em Ciências da Saúde (LILACS) e Base de Dados em Enfermagem (BDENF).

Os descritores utilizados na busca foram: "morte" e "ensino", conforme as descrições de cada um pelos Descritores em Ciências da Saúde (DeCS), e empregou-se, juntamente, o operador boleano $A N D$. Limitou-se a esses, pois, ao associar um terceiro descritor os artigos eram escassos, impossibilitando uma pesquisa aprofundada. Os estudos encontrados datam do ano de 1998 ao ano de 2010.

Estabeleceram-se como critérios de inclusão para seleção: artigos publicados em periódicos brasileiros, para obter um parâmetro nacional sobre o retrato da morte e o ensino nessa temática; texto completo disponível em suporte eletrônico e atender aos objetivos do estudo. Os critérios de exclusão foram: monografias, teses, dissertações, bem como apenas resumo disponível on-line.

Perante o exposto, foram encontrados 111 artigos na totalidade, destes, 78 estavam no LILACS e 33 na BDENF. Portanto, no LILACS, dos 78 encontrados, selecionaram-se 13 artigos e na BEDENF, dos 33 selecionou-se um, totalizando 14 artigos para análise dos dados.

Destaca-se ainda que, cinco artigos disponíveis na BDENF se encaixaram nos critérios de inclusão, porém, já estavam disponíveis no LILACS em texto completo. Assim restou apenas um diferenciado dos demais.

Em seguida, a coleta de dados procedeu a partir da leitura criteriosa dos títulos, resumos e conteúdos dos artigos. Na sequência, catalogaram-se os artigos em ficha de análise documental adaptada e organizada da seguinte forma: autores, periódico/ ano, título, objetivo, desenho do estudo e resultados.

Após, analisaram-se os dados a partir da técnica de Análise Temática, que "consiste em descobrir os núcleos de sentido que compõem uma comunicação cuja presença ou frequência signifiquem alguma coisa para o objetivo analítico visado"(9), e o tema "é a unidade de significação que se liberta naturalmente de um texto analisado segundo critérios relativos à teoria que serve de guia à leitura"(9). Para proceder à análise temática foi organizado e estruturado o conteúdo dos dados seguindo as fases sequenciais: a pré-análise, a exploração do material e o tratamento dos resultados ${ }^{(10)}$.

Quanto aos aspectos éticos, salienta-se que os preceitos de autoria e referenciamento das obras consultadas foram respeitados. Como o estudo configura-se uma revisão integrativa da produção existente e disponível sobre a temática, entendeu-se aceitável dispensar sua submissão a um Comitê de Ética em Pesquisa.

\section{RESULTADOS}

Para a consolidação dos resultados deste estudo, na presente revisão integrativa, analisaram-se 14 artigos que atenderam aos critérios de inclusão previamente estabelecidos, sendo que os mesmos foram analisados na íntegra, a fim de caracterizá-los, interpretá-los e discutí-los, oportunizando com isso sugestões para pesquisas futuras.

A síntese desses estudos encontrados está disposta no Quadro 1.

\section{DISCUSSÃO}

Com base nos materiais analisados, foi possível tecer considerações importantes a serem relatadas com relação ao modo como a morte e o ensino dessa temática são retratados, as quais foram agrupadas nos seguintes pilares temáticos, discutidos a seguir: um retrato da morte e abordagem do processo de morrer e morte no ensino acadêmico.

\section{Um retrato da morte}

Em alguns artigos analisados a morte e a finitude são retratados como características intrínsecas, ou ontológicas, dos sistemas vivos, os 


\begin{tabular}{|c|c|c|c|}
\hline Autor/Ano & Objetivo & Desenho do estudo & Resultado \\
\hline $\begin{array}{l}\text { Bellato, Araujo, } \\
\text { Ferreira, Rodri- } \\
\text { gues, } 2007\end{array}$ & $\begin{array}{l}\text { Analisar a existência de uma } \\
\text { possível correlação entre o } \\
\text { perfil profissional de docentes } \\
\text { e o seu preparo para a aborda- } \\
\text { gem da temática do processo de } \\
\text { morrer e da morte }\end{array}$ & $\begin{array}{l}\text { Qualitativo e descritivo } \\
\text { Questionário } \\
\text { Docentes enfermeiros }\end{array}$ & $\begin{array}{l}\text { Os docentes abordam a } \\
\text { temática morte e morrer } \\
\text { de forma pontual e super- } \\
\text { ficial em suas disciplinas }\end{array}$ \\
\hline $\begin{array}{l}\text { Bernieri, } \\
\text { Hirdes, } 2007\end{array}$ & $\begin{array}{l}\text { Investigar o preparo dos aca- } \\
\text { dêmicos de enfermagem frente } \\
\text { à morte }\end{array}$ & $\begin{array}{l}\text { Qualitativo } \\
\text { Entrevista } \\
\text { Acadêmicos de Enfer- } \\
\text { magem }\end{array}$ & $\begin{array}{l}\text { Os acadêmicos tem di- } \\
\text { ficuldade em lidar com } \\
\text { a morte dos pacientes } \\
\text { assistidos em estágio. }\end{array}$ \\
\hline $\begin{array}{l}\text { Bifulco, Iochida, } \\
2009\end{array}$ & $\begin{array}{l}\text { Tratar de algumas questões } \\
\text { fundamentais relacionadas } \\
\text { com a filosofia dos cuidados } \\
\text { paliativos }\end{array}$ & $\begin{array}{l}\text { Qualitativo } \\
\text { Questionário } \\
\text { Equipe multiprofissional }\end{array}$ & $\begin{array}{l}\text { Os profissionais da saúde } \\
\text { precisam ser capacitados } \\
\text { por meio de educação } \\
\text { continuada para enfren- } \\
\text { tar a morte }\end{array}$ \\
\hline $\begin{array}{l}\text { Bousso, Poles, } \\
\text { Rossato, } 2009\end{array}$ & $\begin{array}{l}\text { Apresentar a importância do } \\
\text { desenvolvimento de conceitos } \\
\text { para a construção do corpo de } \\
\text { conhecimentos em Tanatologia } \\
\text { e Enfermagem }\end{array}$ & $\begin{array}{l}\text { Qualitativo } \\
\text { Reflexão teórica }\end{array}$ & $\begin{array}{l}\text { É preciso avanço no ensi- } \\
\text { no e na pesquisa sobre os } \\
\text { cuidados no final da vida } \\
\text { em pediatria }\end{array}$ \\
\hline $\begin{array}{l}\text { Carvalho, Vale, } \\
2006\end{array}$ & $\begin{array}{l}\text { Investigar como a morte, no } \\
\text { contexto da educação na área } \\
\text { da saúde, pode se constituir } \\
\text { um momento de humanizar o } \\
\text { processo educativo }\end{array}$ & $\begin{array}{l}\text { Qualitativo } \\
\text { Entrevista } \\
\text { Docentes enfermeiros }\end{array}$ & $\begin{array}{l}\text { O cotidiano da relação } \\
\text { aluno-professor revelou- } \\
\text {-se uma vivência solitá- } \\
\text { ria, mas não impossível } \\
\text { de esconder e abafar }\end{array}$ \\
\hline $\begin{array}{l}\text { Covolan, Cor- } \\
\text { rêa, Hoffmann- } \\
\text {-Horochovski, } \\
\text { Murata, } 2010\end{array}$ & $\begin{array}{l}\text { Nomear, debater e discorrer } \\
\text { sobre as possibilidades e os } \\
\text { limites da biotecnologia no } \\
\text { contexto das incapacidades } \\
\text { físico-funcionais }\end{array}$ & $\begin{array}{l}\text { Qualitativo } \\
\text { Relato de experiência }\end{array}$ & $\begin{array}{l}\text { Os pressupostos bioéti- } \\
\text { cos no processo de ensino } \\
\text { aprendizagem são necessá- } \\
\text { rios para alicerçar o debate } \\
\text { sobre direitos e deveres } \\
\text { individuais e coletivos }\end{array}$ \\
\hline $\begin{array}{l}\text { Domingos, } \\
\text { Maluf, } 2003\end{array}$ & $\begin{array}{l}\text { Examinar experiências de per- } \\
\text { da e luto de escolares sobre- } \\
\text { viventes de perdas de entes } \\
\text { queridos por morte }\end{array}$ & $\begin{array}{l}\text { Qualitativo } \\
\text { Entrevista } \\
\text { Escolares entre } 13 \text { a } 18\end{array}$ & $\begin{array}{l}\text { As perdas resultantes } \\
\text { de homicídio, suicídio e } \\
\text { AIDS, foram as mais di- } \\
\text { fíceis de serem expressas } \\
\text { e compartilhadas }\end{array}$ \\
\hline $\begin{array}{l}\text { Guedes, Ohara, } \\
\text { Silva, } 2008\end{array}$ & $\begin{array}{l}\text { Compreender o significado } \\
\text { atribuído por docentes, em te- } \\
\text { rapia intensiva, ao processo de } \\
\text { ensinar e aprender }\end{array}$ & $\begin{array}{l}\text { Qualitativo } \\
\text { Entrevista Fenomeno- } \\
\text { lógica } \\
\text { Docentes enfermeiros }\end{array}$ & $\begin{array}{l}\text { A vivência com os alu- } \\
\text { nos permite o encon- } \\
\text { tro docente/discente, } \\
\text { facilitando o processo de } \\
\text { ensino-aprendizagem }\end{array}$ \\
\hline $\begin{array}{l}\text { Palú, Labronici, } \\
\text { Palini, 2004 }\end{array}$ & $\begin{array}{l}\text { Compreender a percepção de } \\
\text { morte dos profissionais de en- } \\
\text { fermagem no seu cotidiano de } \\
\text { trabalho em uma Unidade de } \\
\text { Terapia Intensiva }\end{array}$ & $\begin{array}{l}\text { Qualitativo } \\
\text { Entrevista } \\
\text { Profissionais de Enfer- } \\
\text { magem }\end{array}$ & $\begin{array}{l}\text { Os trabalhadores desen- } \\
\text { volvem suas atividades } \\
\text { cercadas de muita emoção } \\
\text { e questionamentos, por não } \\
\text { terem sido preparados para } \\
\text { trabalhar com a morte }\end{array}$ \\
\hline
\end{tabular}


Continuação

\begin{tabular}{|c|c|c|c|}
\hline $\begin{array}{l}\text { Paro, Paro, } \\
\text { Ferreira, } 2005\end{array}$ & $\begin{array}{l}\text { Identificar o conhecimento e as } \\
\text { reações do enfermeiro frente ao } \\
\text { cuidar do paciente oncológico } \\
\text { pediátrico }\end{array}$ & $\begin{array}{l}\text { Qualitativo, Descritivo } \\
\text { Entrevista } \\
\text { Enfermeiros }\end{array}$ & $\begin{array}{l}\text { O cuidador possui limi- } \\
\text { ta-ções para enfrentar } \\
\text { situa-ções como morte de } \\
\text { uma criança e necessitam } \\
\text { de suporte para vivenciar } \\
\text { este luto }\end{array}$ \\
\hline Schramm, 2002 & $\begin{array}{l}\text { Apresentar os conceitos de } \\
\text { morte e finitude, articulados } \\
\text { com os conceitos de vulnerabi- } \\
\text { lidade e proteção }\end{array}$ & $\begin{array}{l}\text { Qualitativo } \\
\text { Reflexão teórica }\end{array}$ & $\begin{array}{l}\text { A integralidade da ex- } \\
\text { periência do viver que } \\
\text { implica no morrer exi- } \\
\text { ge um enriquecimento } \\
\text { meta-físico para o jovem } \\
\text { profissional }\end{array}$ \\
\hline $\begin{array}{l}\text { Susaki, Silva, } \\
\text { Possari, } 2006\end{array}$ & $\begin{array}{l}\text { Verificar se o enfermeiro con- } \\
\text { segue identificar as cinco fases } \\
\text { do processo de morrer nos } \\
\text { pacientes sob seus cuidados e } \\
\text { que se encontram fora de pos- } \\
\text { sibilidades terapêuticas }\end{array}$ & $\begin{array}{l}\text { Quanti-qualitativo } \\
\text { Entrevista } \\
\text { Enfermeiros }\end{array}$ & $\begin{array}{l}\text { Constatou-se que } 92 \% \\
\text { dos enfermeiros conse- } \\
\text {-guiram identificar pelo } \\
\text { menos uma das fases do } \\
\text { processo de morrer na } \\
\text { vivência com pacientes } \\
\text { terminais }\end{array}$ \\
\hline $\begin{array}{l}\text { Valsecchi, } \\
\text { Nogueira, } 2002\end{array}$ & $\begin{array}{l}\text { Identificar aspectos positivos/ } \\
\text { negativos relacionados à pres- } \\
\text { ta-ção de assistência em estágio } \\
\text { supervisionado, a partir da } \\
\text { técni-ca dos incidentes críticos }\end{array}$ & $\begin{array}{l}\text { Qualitativo e descritivo } \\
\text { Entrevista } \\
\text { Acadêmicos de Enfer- } \\
\text { magem do } 2^{\circ}, 3^{\circ} \text { e } 4^{\circ} \\
\text { semestres }\end{array}$ & $\begin{array}{l}\text { Identificou-se } 50,5 \% \text { dos } \\
\text { relatos positivos e } 49,5 \% \\
\text { negativos. A positividade } \\
\text { foi atribuída à presença } \\
\text { solidária do professor e } \\
\text { a negatividade à insen- } \\
\text { si-bilidade dos profis- } \\
\text { sionais frente à dor e à } \\
\text { morte }\end{array}$ \\
\hline $\begin{array}{l}\text { Vianna, Picceli, } \\
1998\end{array}$ & $\begin{array}{l}\text { Determinar o perfil do estudan- } \\
\text { te, do médico e do professor de } \\
\text { medicina diante da morte de } \\
\text { pacientes terminais }\end{array}$ & $\begin{array}{l}\text { Quantitativo } \\
\text { Entrevista } \\
\text { Médicos, Acadêmicos e } \\
\text { Docentes de Medicina }\end{array}$ & $\begin{array}{l}\text { Evidenciou que um nú- } \\
\text { mero considerável de } \\
\text { médicos e professores } \\
\text { permanece com muita } \\
\text { dificuldade para tratar } \\
\text { sobre a morte, chegando } \\
\text { mesmo a evitá-la }\end{array}$ \\
\hline
\end{tabular}

Quadro 1 - Descrição dos artigos selecionados segundo autor/ano, objetivo, desenho do estudo e resultados. Santa Maria, RS, 2011.

quais são sistemas jogados no mundo e situados no tempo, submetidos, portanto, a um processo irreversível que inclui o nascer, o crescer, o decair e o morrer ${ }^{(11-12)}$.

Em antítese, apesar do ser humano ter consciência da própria morte, pouco se fala dela, procura-se negá-la, jogá-la para os bastidores da vida normal ${ }^{(12-14)}$. Ela faz parte de um processo na- tural do ponto de vista biológico e está carregada de simbolismo, construído socialmente, impregnado de valores e significados que dependem do contex to histórico e cultural no qual o sujeito está inserido $^{(9,13,15)}$.

O mundo ocidental transformou a morte em tabu, visto que ela costuma ser ocultada das crianças e banida das conversas cotidianas. Os sentimentos 
que ela faz aflorar são tão intensos que seu nome não deve nem ser pronunciado. Por si só ela causa medo, fuga e espanto ${ }^{(10,16)}$. Porém, conhecemos a morte somente mediante o processo de morrer dos outros, cujas vivências jamais nos serão acessíveis em sua real dimensão ${ }^{(14,17)}$.

Algumas produções tratam que as perdas, no geral, suscitam sentimentos de tristeza, ressentimento, dor, autocomiseração, desespero, resignação, desorientação e, particularmente, culpa pela impotência de não ter podido evitar a morte, bem como raiva e revolta contra o destino visto como injusto ${ }^{(10,17-19)}$.

A morte invade todos os espaços e sua onipresença implícita ou explícita detona angústias difusas e paralisantes. Afasta-se a vida com o mesmo objetivo pelo qual se afasta a morte: para preservá-la. Por meio do afastamento de uma ou de outra, se mantém a distância necessária à perpetuação da dissociação( ${ }^{(18)}$.

Sob tal aspecto, a morte sempre foi e continuará a ser um grande desafio para os profissionais da área da saúde. A diferença básica entre as pessoas em geral e os profissionais dessa área, é que, na vida destes, a morte faz parte do cotidiano e pode se tornar sua companheira de trabalho diária ${ }^{(20)}$.

Isso acontece porque os profissionais da saúde são frequentemente expostos a situações de enfrentamento da morte de pessoas sobre seus cuidados, sobretudo aqueles que atuam em serviços hospitalares. Apesar desse confronto rotineiro, eles encontram dificuldade em encará-la como integrante da vida e, geralmente, consideram sua presença como resultado do fracasso terapêutico e do esforço pela cura ${ }^{(9)}$.

Por conseguinte, cuidar do ser humano que está morrendo nos faz refletir sobre a fragilidade da vida e, muitas vezes, coloca aquele que cuida frente às suas impotências, ocasionando certo distanciamento/fuga, a fim de evitar prejuízos nos aspectos psicológicos e emocionais ${ }^{(11,14-13,17,21)}$. Esta compreensão da morte como fracasso, está reforçada pela própria formação do profissional, quando, neste momento, se deixam de abordar e promover discussões referentes às concepções e aos sentimentos sobre o morrer e a morte ${ }^{(14)}$.

Em decorrência, a Tanatologia nasce, nos Estados Unidos, como uma ciência interdisciplinar focalizada no estudo da morte e do morrer a partir do conhecimento biopsicossociocultural e da prática holística $^{(16)}$. Nesse contexto, o enfoque tanatológico percebe a morte no prisma da humanização da assistência ao paciente em fase terminal de vida. Assim, requer dos profissionais da saúde conhecimento, disposição, interesse ativo, afetividade, flexibilidade, busca por aprimorar o cuidar, responsabilidade, sensibilidade, capacidade de escutar oportunizando a expressão de sentimentos sem pré-julgamentos ou censuras ${ }^{(18)}$.

A prática assistencial ao paciente em processo de morrer destina-se ao emprego de cuidados paliativos que é visto como uma abordagem que aprimora a qualidade de vida, dos pacientes e familiares, que enfrentam problemas associados com doenças ameaçadoras de vida, através da preservação e alívio do sofrimento por meio da identificação precoce, avaliação correta e tratamento da dor e de outros problemas de ordem física, psicossocial e espiritual $^{(12,19-20,22)}$.

$\mathrm{Na}$ ausência de possibilidade de cura, as doenças precisam ser "administradas" até o final da vida do paciente, visto que nesse processo de terminalidade emergem atitudes e reações emocionais suscitadas pela aproximação da morte, reações humanas que não dependem de um aprendizado só cultural. Então, essas atitudes e reações são dividas em cinco estágios: a negação, a raiva, a barganha, a depressão e a aceitação ${ }^{(22)}$.

Em síntese, acredita-se ser necessário maiores subsídios à implementação da estrutura organizacional de ensino e assistência em saúde ${ }^{(18)}$. De forma a fornecer recursos que permitam momentos nos quais os profissionais de saúde encontrem apoio e segurança, reciclem seus conhecimentos sobre a doença e atividades nesta área, para também dar suporte a díade familiar-paciente inseridos no processo de morrer e morte.

\section{Abordagem do processo de morrer e morte no ensino acadêmico}

As produções científicas analisadas apontam que, a morte na situação da aprendizagem, na formação de profissionais da saúde, é matriz geradora de conflitos, de estresse que interferem negativamente na relação educativa ${ }^{(11)}$. Todavia, compete ao educador encaminhar o educando para a descoberta e a prática dos valores por intermédio dos quais a educação ganha sentido e o próprio educando se auto-realiza ${ }^{(19,21)}$. 
A sociedade ocidental nega a morte, e a educação, que é oferecida aos profissionais da saúde, não se diferencia do restante da sociedade. Por isso, os acadêmicos da saúde não sabem como agir frente às famílias, tanto de doentes terminais, quanto de pacientes que morrem ${ }^{(10,15)}$. Eles demonstraram dificuldade em lidar com a morte e isto denota que, muitas vezes, preferem dedicar-se exclusivamente aos cuidados técnicos e burocráticos, fugindo assim de um contato mais próximo ${ }^{(10)}$.

Alguns autores sugerem que a educação formal sobre o morrer e a morte pode diminuir a dificuldade de tratar do assunto com pacientes terminais, porém, no Brasil, poucas escolas na área da saúde oferecem tal disciplina em seu currículo ${ }^{(15)}$. Há uma grande ênfase em disciplinas que instrumentalizam o profissional no cuidado para a preservação da vida ou cura das doenças, mas pouco ou nenhum respaldo oferecem para abordar o cuidado as pessoas que vivenciam a terminalidade $\mathrm{e}^{(9)}$.

Portanto, na relação educando-educador a figura deste último se reveste de um caráter de maior responsabilidade, daquele que deve conduzir essa relação por um caminho mais brando, mais equilibrado e mais satisfatório, de modo a atingir um conviver sadio e eficaz, capaz de proporcionar a verdadeira ação educativa ${ }^{(11)}$. Ao contrário, os estudos mostram que o docente encontra-se perdido, procurando uma saída na impessoalidade, parecendo tatear na escuridão, se esquivando, esbarrando, desviando, mas não consegue lançar um olhar cuidadoso que permita apreender o existir humano em sua totalidade ${ }^{(11,15)}$.

Nesse aspecto, infere-se, por meio das produções, que o educador pode se sentir inseguro ao tratar o tema morte. Entretanto, não falar, não refletir sobre isso, é não pensar na perda dos que ficam na dor da solidão. Desse modo, ao utilizar esse mecanismo de defesa, ele acaba criando para si uma armadura protetora, que se evidencia como insensibilidade e frieza. Isso prejudica o desenvolvimento do educando, impede-o de crescer humana e profissionalmente ${ }^{(15)}$.

De acordo com a contribuição de alguns autores, nas instituições de ensino e de assistência direta à saúde, concomitante, deve haver a existência de um serviço que oportunize experiências de contato com tecnologias mais simples, que envolvem atitudes como compaixão, respeito, diálogo, comunicação, e com terapêuticas de baixo custo, como o controle da dor e outros sintomas, juntamente com a família e o próprio paciente terminal ${ }^{(11-12,19-20)}$.

Além disso, alguns artigos abordam que investigar a morte, parte da existência humana, no contexto da educação na área da saúde pode se constituir um momento de humanizar o processo educativo e propiciar um agir autêntico, crítico, não rotineiro e criativo nas ações em saúde ${ }^{(10,16-18)}$. Visto que, há necessidade de se rever questões relacionadas com a morte e o morrer na formação profissional, pois os estudos encontrados apontam que há uma lacuna em relação à discussão de tal temática na área do ensino, deixando os profissionais de saúde despreparados para trabalharem com essa realidade ${ }^{(21)}$.

\section{CONSIDERAÇÕES FINAIS}

Por meio desta revisão integrativa, buscou-se conhecer como a morte e o ensino sobre a morte e o morrer tem sido abordados em publicações científicas brasileiras na área da saúde.

Essa síntese dos artigos demonstrou o despreparo dos docentes, discentes e demais profissionais da saúde ao lidar com os pacientes inseridos no processo de morrer e morte, visto que percebem esse evento vital com certo estranhamento, medo e sofrimento. Além disso, evidenciou-se que os cursos de formação, na área da saúde, atribuem pouca ou nenhuma importância à abordagem sobre terminalidade humana, tornando-se uma questão preocupante, haja vista que o encontro do profissional da saúde com a morte é inevitável na rotina diária de serviço.

Diante disso, vislumbra-se como um desafio a construção de um novo olhar, um novo

assistir e repensar as ações empregadas no cuidado sem vistas à cura. Atividade essa que torna angustiante a prática de assistência cotidiana aos profissionais da saúde quando estão frente à morte dos pacientes.

Nesse contexto, acredita-se que a realização de pesquisas destinadas a compreender a representação social dos docentes em saúde, profissionais facilitadores da educação, a cerca do morrer e da morte, poderia ser uma estratégia inicial no processo de transformação do ensino-aprendizagem nessa temática, a fim de desconstruir, construir e/ ou reconstruir pilares formativos na academia, refletidos na vida pessoal e profissional desses sujeitos. 


\section{REFERÊNCIAS}

1 Oliveira WIA, Amorim RC. A morte e o morrer no processo de formação do enfermeiro. Rev Gaúcha Enferm. 2008; 29(2):191-8.

2 Mota MS, Gomes GC, Coelho MF, Lunardi Filho WD, Sousa LD. Reações e sentimentos de profissionais da enfermagem frente à morte dos pacientes sob seus cuidados. Rev Gaúcha Enferm. 2011; 32(1):129-35.

3 Ross EK. Sobre a morte e o morre. São Paulo: Editora Martins Fontes; 2005.

4 Ramos R. Minidicionário Luft. São Paulo: Editora Ática; 2001.

5 Descritores em Ciências da Saúde (DECS). Morte [Internet]. 2010 [citado 2011 jun 20]. Disponível em: http://decs.bvs.br/cgi-bin/wxis 1660.exe/decsserver/.

6 Pessini L. Cuidados paliativos: alguns aspectos conceituais, biográficos e éticos. Rev Práticas Hospitalares. 2005; 41(7): 107-12

7 Mendes KDS, Silveira RCCP, Galvão CM. Revisão integrativa: método de pesquisa para a incorporação de evidências na saúde e na enfermagem. Texto Contexto Enferm. 2008; 17(4): 758-64.

8 Minayo MCS. Pesquisa Social: teoria, método e criatividade. Petrópolis: Editora Vozes; 2001.

9 Bellato R, Araujo AP, Ferreira HF, Rodrigues PF. A abordagem do processo do morrer e da morte feita por docentes em um curso de graduação em enfermagem. Acta Paul Enferm. 2007; 20(3): 255-263.

10 Bernieri J, Hirdes A. O Preparo dos acadêmicos de Enfermagem brasileiros paravivenciarem o processo morte-morrer. Texto Contex to Enferm. 2007; 16(1): 89-96.

11 Carvalho MDB, Valle ERM. Vivência da morte com o aluno na prática educativa. Ciênc Cuid Saúde. 2006;5(supl):26-32.

\section{Endereço da autora / Dirección del autor / Author's address}

Márcia Gabriela Rodrigues de Lima

Rua Afonso Potter, 2077, Centro

97200-000, Restinga Seca, RS

E-mail:grlmarcia@yahoo.com.br
12 Schramm FR. Morte e finitude em nossa sociedade: implicações no ensino dos cuidados paliativos. Rev Bras Cancerol. 2002; 48(1): 17-20.

13 Covolan NT, Corrêa CL, Hoffmann-Horochovski MT, Murata MPF. Quando o vazio se instala no ser: reflexões sobre o adoecer, o morrer e a morte. Rev Bioética. 2010;18(3): $561-71$.

14 Palú LA, Labronici LM, Albini L. A morte no cotidiano dos profissionais de enfermagem de uma unidade de terapia intensiva. Cogitare Enferm. 2004;9(1): 33-41.

15 Vianna A, Piccelli H. O estudante, o médico e o professor de medicina perante a morte e o paciente terminal. Rev Assoc Med Bras. 1998; 44(1): 21-7.

16 Bousso RS, Poles K, Rossato LM. Desenvolvimento de conceitos: novas direções para a pesquisa em tanatologia e enfermagem. Rev Esc Enferm. USP. 2009;43(spe2): 1331-1336.

17 Domingos B, Maluf MR. Experiências de perda e de luto em escolares de 13 a 18 anos. Psicol Reflex Crit. 2003; 16(3): 577-589.

18 Paro D, Paro J, Ferreira DLM. O enfermeiro e o cuidar em Oncologia Pediátrica. Arq Ciênc Saúde. 2005;12 (3):151-57.

19 Valsecchi EASS, Nogueira MS. Fundamentos de enfermagem: incidentes críticos relacionados à prestacão de assistência em estágio supervisionado. Rev Latino-Am Enferm. 2002; 10(6): 819-824.

20 Bifulco VA, Iochida LC. A formação na graduação dos profissionais de saúde e a educação para o cuidado de pacientes fora de recursos terapêuticos de cura. Rev Bras Educ Méd. 2009;33(1):92 -100.

21 Guedes GF, Ohara CVS, Silva GTR. Processo de ensinar e aprender em UTI: um estudo fenomenológico. Rev Bras Enferm. 2008;61(6):828-834.

22 Susaki TT, Silva MJP; Possari JF. Identificação das fases do processo de morrer pelos profissionais de Enfermagem. Acta Paul Enferm. 2006;19(2):144-149.

Recebido em: 15.08.2011

Aprovado em: 28.03.2012 